\title{
Is Alacrima So Prevalent in Patients With Early-Onset Achalasia?: Author's reply
}

TO THE EDITOR: The Schirmer (Shirmer) I test is one of the old tests available for dry eye diagnosis and is a test to measure reflex tear secretion. ${ }^{1}$ It is performed on unanesthetised eyes. A standard filter paper is placed with its notched tip bent around the lower lid margin at the junction of the middle and outer third. With the eyes closed for 5 minutes, the Schirmer paper is measured from the notch to the leading wetted edge. It is interpreted as dry eye when the wetted part of the filter paper is $<6 \mathrm{~mm}$, as dry eye suspect with 6-10 $\mathrm{mm}$ and as normal with $>10 \mathrm{~mm}$. ${ }^{2,3}$

The diagnostic criteria of dry eye by the Schirmer I test are known to vary from less than $5 \mathrm{~mm} / 5 \mathrm{~min}$, narrow criterion, and to less than $10 \mathrm{~mm} / 5 \mathrm{~min}$, broad criterion. ${ }^{3-5}$ In our article, we chose a broad cut-off value of less than $10 \mathrm{~mm} / 5 \mathrm{~min}$ which is used widely, because we wanted to enroll as many patients as possible for our study. ${ }^{6,7}$ With the narrow cut-off value of less than 5 $\mathrm{mm} / 5 \mathrm{~min}$, the prevalence of alacrima was $26.3 \%$ (5 out of $19 \mathrm{en}-$ rolled patients), lower than that in our original article. By the way, all the 5 patients revealed $0 \mathrm{~mm}$ of paper length in at least one eye.

The relatively low reproducibility and varying diagnostic yield of the Schirmer I test might be one of the limitations of our study. ${ }^{4}$

The previous study of Verma et $\mathrm{al}^{8}$ reported the $20 \%$ prevalence of alacrima with the Schirmer II test using the $5 \mathrm{~mm} / 5 \mathrm{~min}$ cut-off value regardless of the onset of achalasia. When we used the more strict cut-off value in Schirmer I test (less than $5 \mathrm{~mm} / 5$ $\min$ ), $26.3 \%$ of early-onset achalasia showed alacrima. However, the other 3 patients in 19 patients, who could be regarded as alacrima with a broad cut-off value of less than $10 \mathrm{~mm} / 5 \mathrm{~min}$, showed somewhere between 6 and $7 \mathrm{~mm} / 5 \mathrm{~min}$ and a total of 8 patients
(41.5\%) were analyzed as an alacrima. Because of the relatively small numbers of achalasia patients enrolled in our article, further studies based on more numbers of achalasia patients might be needed to define the association between achalasia and alacrima.

Kee Wook Jung

Asan Medical Center, University of Ulsan College of Medicine, Seoul, Korea

1. Kashkouli MB, Pakdel F, Amani A, Asefi M, Aghai GH, Falavarjani KG. A modified Schirmer test in dry eye and normal subjects: open versus closed eye and 1-minute versus 5 -minute tests. Cornea 2010;29:384-387.

2. Kaercher T, Bron AJ. Classification and diagnosis of dry eye. Dev Ophthalmol 2008;41:36-53.

3. Wang HF, Fukuda M, Shimomura Y. Diagnosis of dry eye. Semin Ophthalmol 2005;20:53-62.

4. Nichols KK, Mitchell GL, Zadnik K. The repeatability of clinical measurements of dry eye. Cornea 2004;23:272-285.

5. Danjo Y. Diagnostic usefulness and cutoff value of Schirmer's I test in the Japanese diagnostic criteria of dry eye. Graefes Arch Clin Exp Ophthalmol 1997;235:761-766.

6. Jung KW, Yoon IJ, Kim do $\mathrm{H}$, et al. Genetic evaluation of ALADIN gene in early-onset achalasia and alacrima patients. J Neurogastroenterol Motil 2011;17:169-173.

7. Kim HM. Is Alacrima so prevalent in patients with early-onset achalasia? J Neurogastroenterol Motil 2011;17:330.

8. Verma S, Brown S, Dakkak M, Bennett JR. Association of adult achalasia and alacrima. Dig Dis Sci 1999;44:876-878.

Conflicts of interest: None. 